\title{
MEDIA PEMBELAJARAN KAMUS TIGA BAHASA NEGARA BERBASIS ANDROID
}

\author{
Nora Yuris Prudensi ${ }^{1}$, Masrizal $^{2}$, Musthafa Haris Munandar ${ }^{3)}$ \\ 1,2,3Fakultas Sains dan Teknologi, Universitas Labuhanbatu \\ Email: yurisprudensi16@gmail.com,masrizal120405@gmail.com, \\ harismunandaaar@gmail.com
}

\begin{abstract}
The purpose of this study is to create a dictionary application in three languages that can help users to make it easier to search for English, Korean and Indonesian vocabulary. Dictionary of 3 State Languages is a learning media that can provide convenience for students and the general public. The phenomenon that occurs is that students in the class have problems with foreign languages to complete the tasks given by the teacher in fulfilling the learning contributions needed in the learning process in foreign language subjects. This application is designed using UML, Eclipse and SQLite database. The design of this application is very useful for students, teachers, and even the general public. The method used in designing this application is the Waterfall System Development Life Cycle method. The stages carried out consist of data collection, analysis of problems and requirements, and testing. Data collected from Indonesian dictionaries, Japanese dictionaries, English dictionaries and preparatory software is required to build an application. The next step is to build an application with Eclipse and the last process is to complete the application and implement it to an android device which provides vocabulary translation services into three languages at once..
\end{abstract}

Keywords: Android, Foreign Language, Dictionary, Application

\section{PENDAHULUAN}

Bahasa merupakan suatu perwujudan manusia dalam berkomunikasi. Definisi ini mempunyai sebutan yang berarti, masingmasing dipisah menjadi sebagian detail, antara lain adalah sebutan sebagai sistem, ciri-ciri, vokal, konvesional, dan komunikasih. Bahasa merupakan suatu fenomenal yang mengkaitkan proses yang beragam semacam pengenalan bunyi, huruf, serta pula komunikasih emosional lewat irama bicara serta pergantian nada bicara.

Bahasa merupakan komunikasi dua arah yang penting dalam kehidupan sehari-hari[1]

Biasanya orang menekuni suatu bahasa, seperti bahasa Inggris dan bahasa Korea memakai buku bacaan yang bersumber dari institusi pembelajaran. Selain itu dapat pula dilakukan dengan cara belajar sendiri atau pun hanya dengan mencermati lagu atau menyaksikan film berbahasa Inggris dan bahasa Korea. Untuk sebagian orang yang baru memahami bahasa Inggris dan bahasa Korea akan mengalamin kesusahan dalam mengartikan kata-kata bahasa Inggris dan bahasa Korea karena banyaknya suku kata dalam kedua bahasa tersebut.

Program pengenalan kepribadian dikenal lewat sesuatu citra masukan dengan suatu perlengkapan pemindai ataupun kamera digital serta fitur lunak dalam pc yang masih ada permasalahan dalam dimensi ruang penyimpanan yang ada pada pc serta perlengkapan pemindai. Buat menanggulangi keterbatasan pada pc yang umumnya menghabiskan memori besar hingga suatu sistem pengenalan kepribadian berbasis ponsel pintar diajukan. Android merupakan sistem operasi yang bersifat opensource [2]. Salah satu pemimpin dalam evolusi smartphone adalah sistem operasi Google Android[3].

Dizaman digital era revolusi 4.0 berbagai aspek kehidupan sudah banyak menggunakan teknologi berbasis komputer [4], [5]-[14]. Bersamaan perkembangan teknologi 
data serta komunikasi telepon pintar (smartphone) berbasis Android tumbuh dengan pesat serta sudah menempel pada kehidupan warga paling utama di golongan pelajar. Tetapi, pemanfaatan smartphone digolongan siswa masih digunakan sebatas perlengkapan komunikasi, belum dimanfaatkan buat media pendidikan. Oleh sebab itu, diperlukan suatu aplikasi yang bisa jadi media pendidikan dengan menggunakan teknologi smartphone tersebut buat pendidikan bahasa asing paling utama bahasa korea serta bahasa Inggris.

\section{METODE PENELITIAN}

\subsection{Pengumpulan Data}

Tata cara riset yang dipakai untuk penelitian ini dilakukan dengan menggunakan metode deskriptif yakni penelitian dilakukan dengan bersumber pada informasi yang sesungguhnya dengan menyamakan teori setelah itu dilanjutkan dengan mengambil kesimpulan.

Tata cara pengumpulan informasi merupakan satu metode yang dipakai buat mengolah informasi dari sesuatu sistem. Agar mendapatkan informasi yang dibutuhkan dalam penataan penelitian ini, penulis memakai tata cara mengumpulkan informasi. Adapun cara pengumpulan informasi yang dilakukan dalam penelitian ini:

1) Wawancara (Interview)

Ialah melaksanakan dua arah secara langsung tentang hal penting kepada pengajar ataupun murid sampai bisa menciptakan informasi serta data yang diperlukan. Ada pula perlengkapan yang digunakan merupakan perlengkapan tulis semacam pena, pensil, serta novel.

2) Pengamatan (Observation)

Ialah sesuatu ataupun proses riset serta mengamati yang dicoba secara terjun langsung kelapangan agar tercapai tujuan mendapatkan informasi.

\section{Learning Method}

Metode yang melaksanakan sumber informasi dengan melihat proses mengajar di ruangan kelas di mana seorang guru yang membagikan latihan kepada siswa/i dengan materi yang diajarkan.

Pada aplikasi ini menyediakan tiga bahasa sekaligus yang dapat dipelajari oleh pengguna, yaitu Bahasa Indonesia - Inggris Korea [15].

\subsection{Metode Perancangan Sistem}

Tahapan ini merupakan tahap desain yang dilakukan untuk mengembangkan sistem yang akan dibangun. Adapun perancangan sistem dibuat terdiri dari :

1. Diagram Konteks

Diagram konteks ini menggambarkan sistem yang sedang berjalan secara keseluruhan.

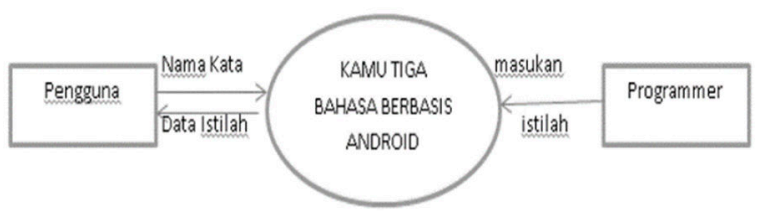

Gambar 1. Diagram Konteks

2. Diagram Level 1

Diagram level 1 ini menunjukkan alir sebuah sistem aplikasi yang akan dikembangkan dalam kamus tiga bahasa berbasis android.

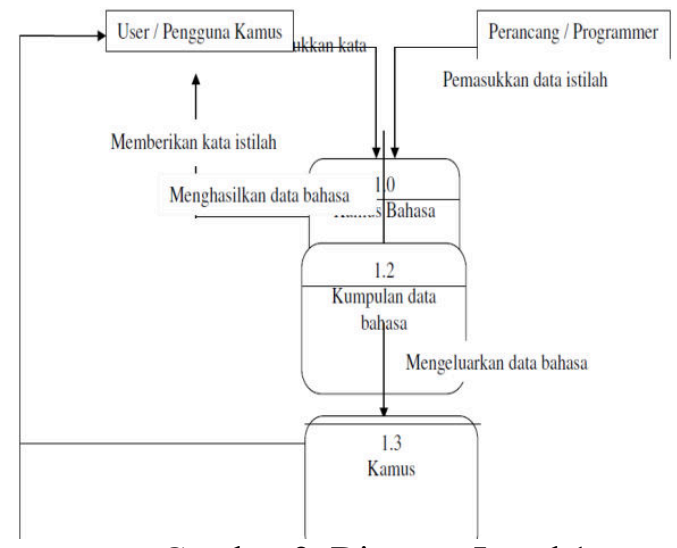

Gambar 2. Diagram Level 1

\section{HASIL DAN PEMBAHASAN}

Perangkat lunak yang dirancang terdiri dari 3 bahasa asing ini yaitu Bahasa Inggris, Korea, Bahasa Indonesia. Dalam perangkat lunak ini akan menampilkan hasil kalimat ketiga bahasa tersebut. Jika kalimat yang dimasukkan 
dalam perangkat ini salah maka akan memberikan notifikasi agar para siswa atau si pengguna dapat menguasai perinci metode 3 bahasa tersebut.

Dengan adanya perangkat lunak ini bisa banyak membantu belajar bahasa Inggris, Bahasa Indonesia dan bahasa Korea agar lebih mahir dan efisien dimanapun pergi bisa digunakan [16].

\subsection{Pembahasan}

Untuk menjalankan aplikasi yang 3 bahasa ini mengguanakan android dapat digunakan offline ataupun online.

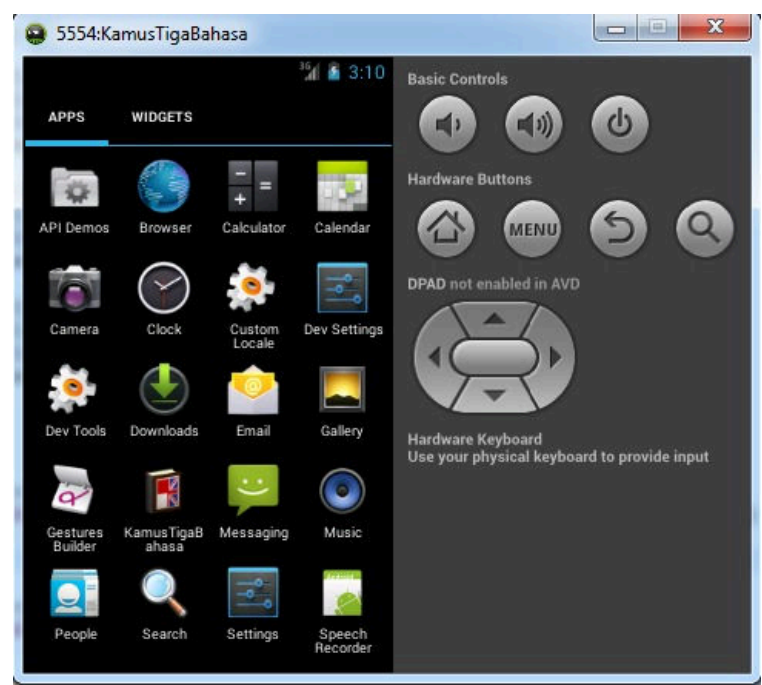

Gambar 3. Icon Aplikasi

Bentuk Masukan

Pengguna agar lebih mudah memasukkan kalimat dalam bentuk kalimat. Contoh kalimat "Luar Biasa". 3 bahasa tersebut terdiri dari bahasa Indonesia, Bahasa Inggris serta Korea. Jika kita menggunakan bahasa inggris maka terjemahan nya akan kebahasa Korea dan Indonesia.

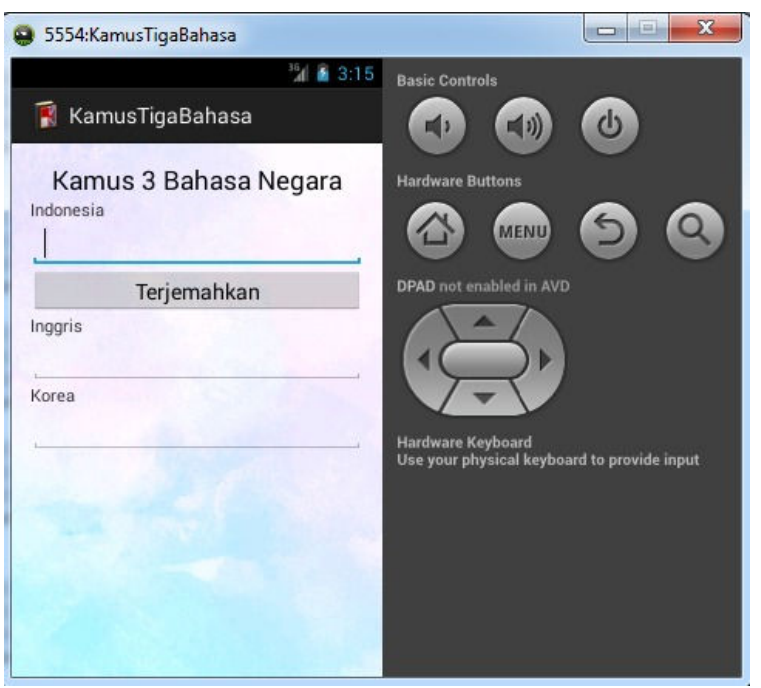

Gambar 4. Tampilan Kalimat.

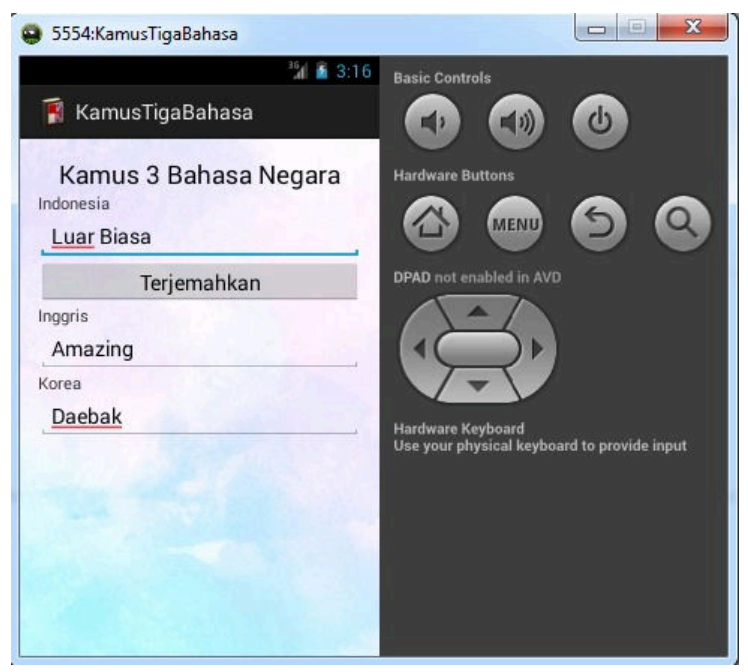

Gambar 5. Tampilan Kalimat 3 Bahasa.

\subsection{Hasil Pengujian Dengan Metode BlackBox}

Hasil pengujian terhadap kamus yang telah dibangun diuji dengan menggunakan metode blackbox dan hasilnya dapat dilihat pada tabel 1.

\begin{tabular}{lllll}
\multicolumn{4}{c}{ Tabel.1. Black Box Penerjemah } & \\
\hline $\mathrm{N}$ & $\begin{array}{c}\text { Skenario } \\
\text { Pengujian }\end{array}$ & $\begin{array}{l}\text { Hasil yang } \\
\text { Diharapkan }\end{array}$ & $\begin{array}{c}\text { Hasil } \\
\text { Pengujian }\end{array}$ & Status \\
& & & & \\
\hline 1 & $\begin{array}{l}\text { Mengosongkan } \\
\text { masukan kata }\end{array}$ & Sistem & Sistem & Berhasil \\
& kemudian & menampil- & menampil & \\
& mengklik & kan kete- & kan kete- & \\
tombol & rangan & rangan & \\
terjemahkan & "Tidak & "Tidak & \\
& ditemukan" & ditemu- & \\
& & & kan" &
\end{tabular}




\begin{tabular}{|c|c|c|c|c|}
\hline $\begin{array}{l}\mathrm{N} \\
\mathrm{o}\end{array}$ & $\begin{array}{l}\text { Skenario } \\
\text { Pengujian }\end{array}$ & $\begin{array}{l}\text { Hasil yang } \\
\text { Diharapkan }\end{array}$ & $\begin{array}{c}\text { Hasil } \\
\text { Pengujian }\end{array}$ & Status \\
\hline 2 & $\begin{array}{l}\text { Mengisi kata } \\
\text { yang tidak } \\
\text { sesuai } \\
\text { kemudian } \\
\text { menekan } \\
\text { tombol } \\
\text { terjemahkan }\end{array}$ & $\begin{array}{l}\text { Sistem } \\
\text { tidak } \\
\text { menerjema } \\
\text { hkan dan } \\
\text { memberi- } \\
\text { kan kete- } \\
\text { rangan } \\
\text { "Tidak } \\
\text { ditemukan" }\end{array}$ & $\begin{array}{l}\text { Sistem } \\
\text { tidak } \\
\text { menerje- } \\
\text { mahkan } \\
\text { dan } \\
\text { memberi- } \\
\text { kan kete- } \\
\text { rangan } \\
\text { "Tidak } \\
\text { ditemu- } \\
\text { kan" }\end{array}$ & Berhasil \\
\hline 3 & $\begin{array}{l}\text { Mengisi kata } \\
\text { dengan benar } \\
\text { kemudian } \\
\text { menekan } \\
\text { tombol } \\
\text { terjemahkan }\end{array}$ & $\begin{array}{l}\text { Sistem } \\
\text { memberi- } \\
\text { kan hasil } \\
\text { terjemahan } \\
\text { dari kata } \\
\text { yang diter- } \\
\text { jemahkan }\end{array}$ & $\begin{array}{l}\text { Sistem } \\
\text { memberi- } \\
\text { kan hasil } \\
\text { terjema- } \\
\text { han dari } \\
\text { kata yang } \\
\text { diterjemah } \\
\text { kan }\end{array}$ & Berhasil \\
\hline
\end{tabular}

\section{KESIMPULAN}

Penggunaan perangkat lunak Kamus 3 bahasa berbasis android ini untuk membantu murid atau pengguna dalam menerjamahkan ke 3 bahasa tersebut dengan menggunakan handphone pintar yang berbasis android.

Aplikasi ini juga lebih ringan digunakan di dalam perangkat android karena sudah di dukung berbagai fitur canggih yang tertanam di dalamnya.

\section{REFERENSI}

[1] A. Amri, S. Sarkum, and I. Purnama, "Media Pembelajaran Kamus Bahasa Latin Berbasis Android," InfoTekJar (Jurnal Nas. Inform. dan Teknol. Jaringan), vol. 3, no. 1, pp. 60-64, 2018, doi: 10.30743/infotekjar.v3i1.560.

[2] A. Ardian and Purnama, "Perancangan Aplikasi Pengolah Data Siswa Berbasis Android (Studi Kasus : Mis Nurul Huda Labuhan Batu Selatan)," Pengabdi. Masy. Ika Bina En Pabolo, vol. 1, no. 1, pp. 40-53, 2019.

[3] Y. Laia et al., "Android based Optimization and Queue System at Passenger Vessel Services Crossings," Mecn. 2020 - Int. Conf. Mech. Electron. Comput. Ind. Technol., pp. 327-331,
2020, doi: 10.1109/MECnIT48290.2020.9166675.

F. Sinuraya et al., "WEB-BASED FOOD ORDERING INFORMATION SYSTEM STUDI," pp. 7-11, 2021.

A. Ardian, I. Purnama, and V. Sihombing, "Perancangan Aplikasi Pengolah Data Siswa Berbasis Android (Studi Kasus : Mis Nurul Huda Labuhan Batu Selatan)," Pengabdi. Masy. Ika Bina En Pabolo, vol. 1, no. 1, pp. 40-53, 2019.

[6] Fricles Ariwisanto Sianturi, "Analisa metode teorema bayes dalam mendiagnosa keguguran pada ibu hamil berdasarkan jenis makanan," Tek. Inf. dan Komput., vol. 2, no. 1, pp. 87-92, 2019, [Online]. Available: http:/jurnal.murnisadar.ac.id/index.php/ Tekinkom/article/view/78.

[7] V. Sihombing, "Sistem Informasi Penjualan Mobil Suzuki Di Dealer Bagan Batu," SISTEMASI, vol. 7, no. 2, pp. 113-119, 2018.

[8] J. Simatupang, "Perancangan Sistem Inventori Barang pada Toko Nichos Jaya Menggunakan Metode FIFO," J. Intra Tech, vol. 1, no. 1, pp. 31-42, 2017.

[9] G. J. Yanris, “Analisis Dan Implementasi Data Mining Dalam Menganalisa Kendala Akademik Yang Sering Dikeluhkan Mahasiswa AMIK Labuhanbatu (Studi Kasus : Amik Labuhanbatu)," Informatika, vol. 4, no. 1, pp. 15-24, 2016.

[10] V. Sihombing, "Aplikasi Simade (Sistem Informasi Manajemen Desa) Dalam Meningkatkan Pelayanan Administrasi di Kepenghuluan Bakti Makmur Kecamatan Bagan Sinembah Kab. Rokan Hilir Riau," SISTEMASI, vol. 7, no. September, pp. 292-297, 2018.

[11] W. Purba, S. Tamba, and J. Saragih, "The effect of mining data k-means clustering toward students profile model drop out potential," J. Phys. Conf. Ser., 
vol. 1007 , no. 1 , p. 12049,2018 , [Online]. Available:

http://stacks.iop.org/1742$6596 / 1007 / \mathrm{i}=1 / \mathrm{a}=012049$.

[12] V. Sihombing and G. J. Yanris, "PENERAPAN APLIKASI DALAM MENGOLAH ASET DESA (STUDI KASUS: KEPENGHULUAN SRI KAYANGAN)," J. Mantik Penusa, vol. 4, no. 1, pp. 12-15, 2020.

[13] W. Purba, S. Aisyah, and S. P. Tamba, "Perancangan Sistem Pakar Diagnosa Penyakit Mata Katarak Menggunakan Konsep Metode Runut Mundur," JUSIKOM PRIMA (Junal Sist. Inf. Ilmu Komput. Prima), vol. 1, no. 1, 2017.

[14] J. Simatupang and S. Sianturi, "PERANCANGAN SISTEM INFORMASI PEMESANAN TIKET BUS PADA PO. HANDOYO BERBASIS ONLINE," J. Intra Tech, vol. 3, no. 2, pp. 11-25, 2019.

[15] A. Subhan, H. Sulistyanto, and M. Kusban, "Aplikasi kamus tiga bahasa berbasis android," pp. 2-16, 2014.

[16] D. Sukma, "Aplikasi Pembelajaran Tiga Bahasa ( Indonesian- English- German ) Berbasis Android," Bina Insa. Ict J., vol. 3, no. 2, pp. 384-397, 2016. 